\title{
Testosterone Level in Men correlates with BMI and Cardiorespiratory Fitness But Is Not Related to Age.
}

Gruntmanis U, MD; Radford NB, MD; Leonard D, PhD; Gibbons LW, MD; Wilson R, MD; Cooper TC, MD; Clark SM, MD; Laura F DeFina, MD

\section{Cooper Center}

Longitudinal Study

The Cooper Institute

\section{INTRODUCTION}

- Age-related decline in testosterone may be due to causes other than aging alone

- Weight gain, decreased physical activity, low cardiorespiratory fitness (fitness), and chronic illness may play a role in testosterone decline with age

- Testosterone replacement use among men has increased 3-fold in the past decade despite the risks associated with its use

\section{OBJECTIVE}

To determine if testosterone level in relatively healthy males is associated with age, BMI, and/or fitness

\section{METHODS}

- Men were either self-referred or referred by their employer for a comprehensive clinical examination including a maximal treadmil test, testosterone measurement, and measurement of traditional risk factors from January 2012 - December 2012 at the Cooper Clinic, Dallas TX

- Exclusions: use of any form of androgens and 5-alpha-reductase inhibitors

- Morning Total Testosterone Measurement

- Blood drawn between 7 and 9 am following a 12-hour fast

- Standard Chemiluminescence method

- Mean intra-assay and inter-assay coefficients of variation were $<10$ percent

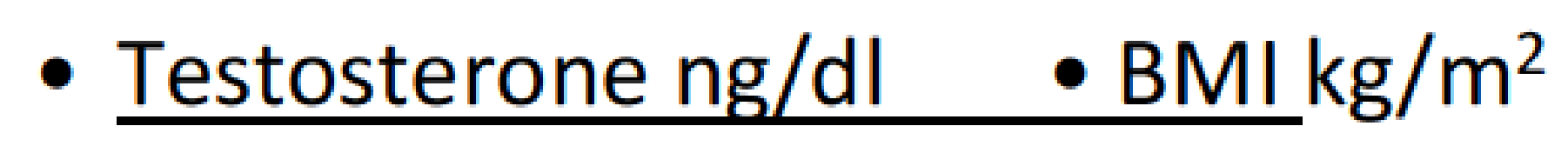

- Low: $<250$

- Lown:250-<400

- Normal: $\geq 400$

- Normal:18.5-24.9

- Overweight: 25-29.9

- Obese: $\geq 30$

\section{STATISTICAL ANALYSIS}

- Cross-sectional analysis of 1464 men

- Means and frequencies were used to summarize characteristics of the sample within decades of age and BMI categories

- Multiple logistic regression was used to test the association between low testosterone and age, $\mathrm{BMI}$, and fitness



*Values are mean (SD) unless otherwise noted

${ }^{+}$Impotence is defined by self-report and/or use of Viagra, Cialis, Levitra, Staxyn, or Trimix

Distribution of Men by Testosterone Category and Decade of Age

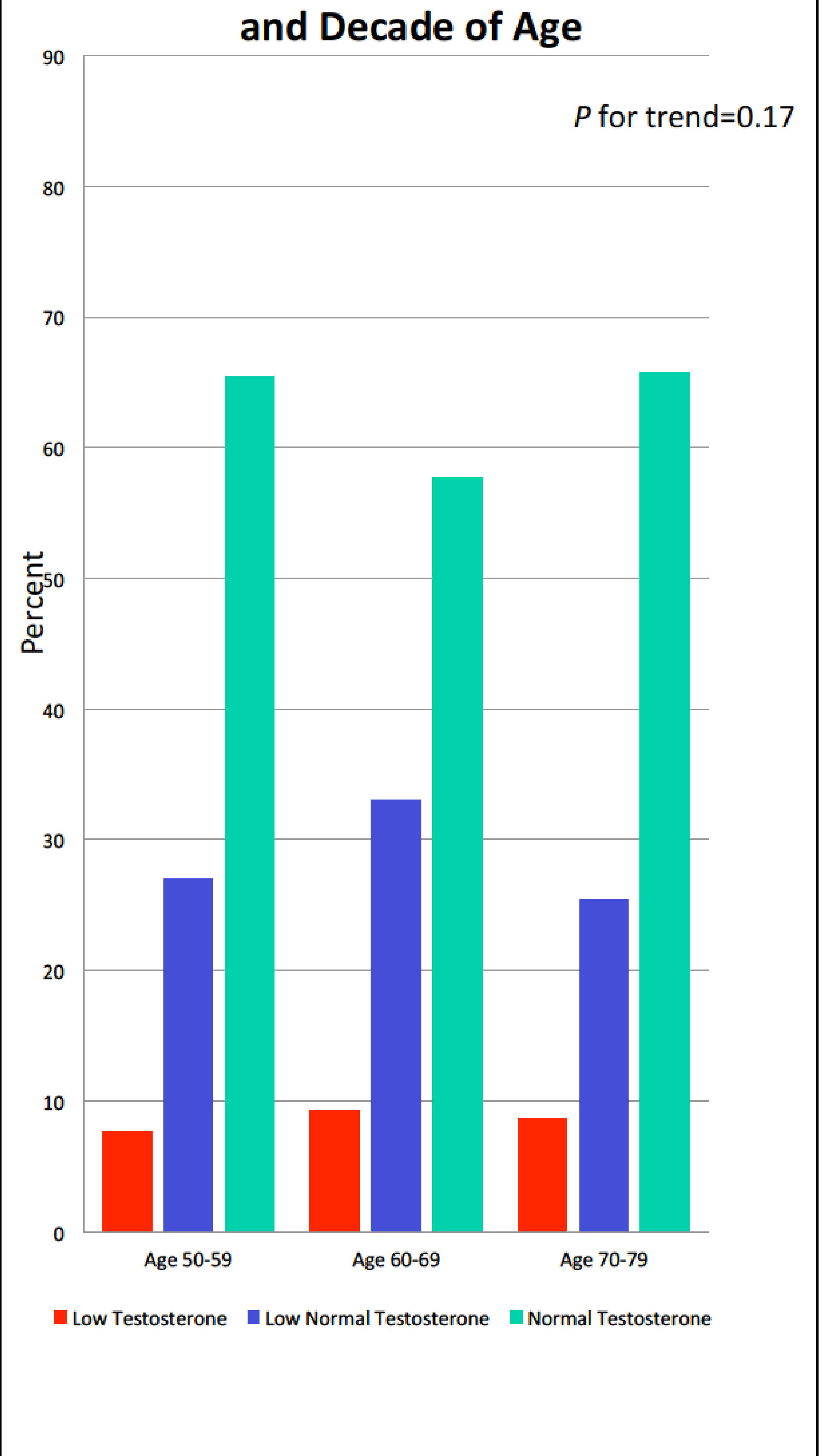

UT SOUTHWESTERN M E D I C A L C E N T E R

Odds of Having Testosterone $<250$ $\mathrm{ng} / \mathrm{dL}$

by Age, BMI, and Cardiorespiratory Fitness

\begin{tabular}{|l|c|c|}
\hline & $\begin{array}{c}\text { Odds Ratio } \\
(\mathbf{9 5 \%} \mathbf{~ C l})\end{array}$ & $\begin{array}{c}\mathbf{p} \\
\text { value }\end{array}$ \\
\hline Age $^{*}$, per year & $\begin{array}{c}1.00 \\
(0.98,1.03)\end{array}$ & 0.85 \\
\hline $\begin{array}{l}\text { Body mass index } \\
\left(\text { BMI }^{*} \text {, per kg/m² }\right.\end{array}$ & $\begin{array}{c}1.15 \\
(1.10,1.20)\end{array}$ & $<0.001$ \\
\hline Fitness $^{*}$, per MET & $\begin{array}{c}0.75 \\
(0.67,0.84)\end{array}$ & $<0.001$ \\
\hline Age $^{\dagger}$, per year & $\begin{array}{c}0.96 \\
(0.92,1.00)\end{array}$ & 0.07 \\
\hline BMI $^{\dagger}$, per kg/m² & $\begin{array}{c}1.08 \\
(1.01,1.16)\end{array}$ & 0.02 \\
\hline Fitness $^{\dagger}$, per MET & $\begin{array}{c}0.78 \\
(0.67,0.91)\end{array}$ & 0.002 \\
& & \\
& & \\
\hline
\end{tabular}

- Unadjusted ${ }^{+}$Multivariate model with age, BMI, and cardiorespiratory fitness

\section{SUMMARY \& IMPLICATIONS}

- Prevalence of low testosterone was not significantly different across decades of age.

- Prevalence of low testosterone was higher with increasing BMI category.

- Mean fitness increased with increasing testosterone category.

- In multivariate models, fitness and BMI were significantly associated with the odds of having low testosterone. Age was not significantly associated with the odds of having low testosterone after adjusting for fitness and BMI.

-Future research should determine if low testosterone levels can be normalized through lifestyle changes such as improved cardiovascular fitness.

\section{ACKNOWLEDGEMENTS}

- Cooper Clinic physicians and staff - Cooper Institute data management team

No potential conflicts of interest exist 